\section{Pengaruh Green Marketing, Inovasi Produk, dan Brand Image Terhadap Minat Beli Studi Pada Mahasiswa Mahasiswi FE UST Konsumen KFC}

Buying Intention of Students for

Fastfood Product

Fika Riskiana Sukma P., Susanto, Lusia Tria Hatmanti H. Fakultas Ekonomi Universitas Sarjanawiyata Tamansiswa, Yogyakarta, Indonesia Email : fikariskiana24@gmail.com
Submitted: DESEMBER 2020

Accepted: MARET 2021

\title{
ABSTRACT
}

This study aims to determine the effect of Green Marketing, Product Innovation, and Brand Image on Buying Interest in KFC Consumer UST FE Student. Many female students currently buy $K F C$ products. In Indonesia itself, there are various kinds of well-known fast food restaurants in this community such as McDonald's, A\&W, Richeese Factory, Hokben, and others. Sometimes we get confused between these restaurants. That's why in this study, researchers want to know what factors influence female students. Researchers narrow down three variables, Green Marketing, Product Innovation, and Brand Image. This research uses quantitative research and selects 100 people (male \& female, 18-26 years old, management or accounting study program and purchasing KFC products) as research subjects. Researchers used the SPSS application to test the results of the study. The results showed that the most influential factor in influencing product purchase intention was Green Marketing, followed by Brand Image, and the last one that had the least influence was Product Innovation.

Keywords: Green Marketing, Product Innovation, Brand Image, Purchase Interest.

\begin{abstract}
ABSTRAK
Penelitian ini bertujuan untuk mengetahui pengaruh Green Marketing, Inovasi Produk, dan Citra Merek terhadap Minat Beli Konsumen KFC Mahasiswa UST FE. Banyak mahasiswi saat ini membeli produk KFC. Di Indonesia sendiri terdapat berbagai macam restoran cepat saji yang terkenal di komunitas ini seperti McDonald's, A\&W, Richeese Factory, Hokben, dan lain-lain. Terkadang kita bingung antara restoran ini. Oleh karena itu dalam penelitian ini peneliti ingin mengetahui faktor-faktor apa saja yang mempengaruhi mahasiswi. Peneliti mempersempit tiga variabel, Pemasaran Hijau, Inovasi Produk, dan Citra Merek. Penelitian ini menggunakan jenis penelitian kuantitatif dan memilih 100 orang (laki-laki \& perempuan, 18-26 tahun, program studi manajemen atau akuntansi dan pembelian produk KFC) sebagai subjek penelitian. Peneliti menggunakan aplikasi SPSS untuk menguji hasil penelitian. Hasil penelitian menunjukkan bahwa faktor yang paling berpengaruh dalam mempengaruhi minat beli produk adalah Pemasaran Hijau, diikuti oleh Citra Merek, dan terakhir yang paling kecil pengaruhnya adalah Inovasi Produk.
\end{abstract}

Kata Kunci: green marketing, inovasi produk, citra merek, minat beli.

\section{PENDAHULUAN}

Perkembangan perindustrian, pengetahuan, teknologi, ekonomi dan bisnis menimbulkan efek negatif bagi lingkungan hidup (Almuarief, 2016). Efek negatif yang kini mulai dibicarakan adalah global warming (Yulianti, Rizka, Wulandari, \& Wulandari, 2014). Lebih lanjut dengan adanya berbagai macam kerusakan lingkungan dan bencana

\section{JIMKES}

Jurnal Ilmiah Manajemen Kesatuan 9 No. 1, 2021 pp. 33-42
IBI Kesatuan ISSN 2337 - 7860 E-ISSN 2721 - 169X 
Buying Intention of yang terjadi akibat dari ulah manusia itu sendiri. Kerusakan hutan dengan membakar Students for Fastfood Product hutan yang dilakukan oleh ulah manusia itu sendiri sehingga menimbulkan asap tebal yang sangat berbahaya bagi pernafasan manusia, perubahan suhu yang tidak pasti, semakin tidak stabilnya iklim, menipisnya lapisan ozon dan lain sebagainnya (Almuarief, 2016).

Pada saat ini, sampah menjadi masalah besar bagi Negara Indonesia terutama sampah plastik (Septifani, Achmadi, \& Santoso, 2014). Berdasarkan data statistik, bahwa peringkat kedua penghasil sampah domestik di Indonesia adalah sampah plastik sebesar 5,4 juta ton per tahun (AntaraNews, 2014) diakses pada 4 Oktober 2019 pukul 19.00. Dimana sampah plastik sulit atau lama untuk terurai. Hal lain yang menjadi pusat perhatian pada akhir-akhir ini adalah banyaknya sampah plastik yang terbuang sembarangan, banyak laut-laut indonesia yang sangat indah mulai tercemar karena limbah plastik. Selain itu ekosistem laut dan banyaknya hewan laut yang mulai rusak dan mati akibat terlalu banyak tercemar dan memakan sampah plastik yang terbuang di laut. Berdasarkan (CNBC Indonesia, 2019) diakses pada Jumat 4 Oktober 2019 pukul 20.00 menyatakan bahwa Indonesia memiliki populasi pesisir sebesar 187,2 juta setiap tahunnya menghasilkan 3,22 juta ton plastik yang tak terkelola dengan baik, sekitar 0,48 - 1,29 juta ton dari sampah plastik tersebut diduga mencemari lautan, dengan jumah pencemaran sampah palstik ke Laut terbesar kedua didunia. Data dari Deputi Pengendalian Pencemaran Kementrian Negara Lingkungan Hidup (KLH) menyebutkan, setiap individu rata-rata menghasilkan 0,8 kilogram sampah dalam satu hari dengan kadar 15 persennya adalah plastik (Nursyfani, 2013).

Masyarakat mulai sadar bahwa produk yang mereka gunakan tidak ramah lingkungan dan menambah sampah plastik (Agustin \& Yulianto, 2015). Konsumen lebih selektif dalam melakukan pemilihan dan pembelian produk sehari-hari (Agustin \& Yulianto, 2015). Masalah lingkungan tersebut bisa saja merupakan suatu peluang atau ancaman bagi para pelaku bisnis (Widodo et al., 2015). Pelaku bisnis yang pintar akan menjadikan isu lingkungan tersebut menjadi suatu peluang serta tantangan untuk menciptakan produk yang sesuai dengan keinginan konsumen untuk meningkatkan penjualan, meningkatkan Citra Perusahaan, dan memenangkan Persaingan Pasar. (Istantia, Kumadji, \& Hidayat, 2016). Seperti yang diterapkan oleh PT. Fast Food Indonesia (KFC). KFC terus berupaya mencari solusi lebih ramah lingkungan untuk semua produknya dan meminimalkan penggunaan sedotan plastik sebagai langkah kecil yang akan berdampak besar bagi lingkungan. Selain itu sejak tahun 2012 KFC telah meluncurkan program Green Action menggunakan Beras Organik lebih menyehatkan karena diproduksi tanpa menggunakan pupuk kimia, di tanam di lahan dan pengairan yang bebas dari pencemaran, serta menggunakan variates pada lokal atau alam (Https://marketing.co.id, 2012).

American Marketing Association (AMA) Hawkins and Mothershaugh (2010) mendefinisikan green marketing adalah suatu proses pemasaran produk-produk yang diasumsikan aman terhadap lingkungan. Green marketing tidak hanya menawarkan produk ramah lingkungan, namun juga mencakup tentang bagimana cara memproduksi, mengemas, serta aktifitas modifikasi produk. Tujuan dari green marketing bukan hanya mencari keuntungan, namun perusahaan menginginkan adanya pertumbuhan kepedulian terhadap lingkungan hidup. Menurut pendapat Polonsky (1995) dalam (Sumarwan, 2012) menyebutkan bahwa green marketing tidak hanya memasarkan produk ramah lingkungan, tetapi menuntut adanya reorientasi dan tanggung jawab lingkungan dari keseluruhan area, aktivitas, dan departemen dari suatu organisasi.

Menurut (Kotler, Philip, 2012) produk adalah segala sesuatu yang ditawarkan ke pasar untuk memenuhi kebutuhan dan keinginan. Inovasi merupakan bagian penting dalam pemasaran karena kaitan erat dengan menghindarkan konsumen kejenuhan dan membuat produk yang ditawarkan perusahaan memiliki daya tarik yang kuat. Menurut Myers and Marquis dalam Kotler, (2007) menyatakan inovasi produk adalah gabungan dari berbagai macam proses yang saling mempengaruhi antara yang satu dengan yang lain. 
Tjiptono (2008) menyatakan definisi merek sebagai nama, istilah, symbol, atau lambing, desain warna, gerak atau kombinasi atribut-atribut produk lainnya yang diharapkan dapat memberikan identitas dan sebagai pembeda terhadap produk pesaing. Kotler dan Keller (2007) juga mendefinisikan bahwa merek adalah nama, istilah, tanda, atau lambing, atau desain, atau kombinasinya, yang dimaksudkan untuk mengidentifikasi barang atau jasa pesaing.

Crosno et al. dalam Ghalandri dan Norouzi (2012) mendefinisikan minat beli konsumen sebagai kemungkinan konsumen dalam memilih suatu merek kategori produk suatu dalam situasi pembelian tertentu Pengertian minat beli menurut Setiawan dan Ihwan (2004) terdapat beberapa pengertian, yaitu: a. Minat beli mengarah kepada individu yang memiliki kemauan untuk membeli, $b$. Minat beli juga dapat dijadikan sebagai tolak ukur keinginan seseorang dalam membeli, c. Minat beli berhubungan dengan perilaku pembelian yang dilakukan secara terus menerus

Penelitian ini memiliki rumusan masalah sebagai berikut :

a. Apakah green Marketing berpengaruh terhadap minat beli pada KFC Yogyakarta?

b. Apakah inovasi produk berpengaruh terhadap minat beli pada KFC Yogyakarta?

c. Apakah Brand Image berpengaruh terhadap minat beli pada KFC Yogyakarta?

d. Apakah Green Markeing, Inovasi Produk dan Brand Image berpengaruh terhadap minat beli pada KFC Yogyakarta?

\section{Penelitian Terdahulu}

Ambarwati et al (2015) telah melakukan penelitian dengan judul Pengaruh Citra Merek Terhadap Minat Beli (Survei Pada Mahasiswa Universitas Brawijaya Yang Menggunakan Pasta Gigi Pepsodent). Eksplanatory research merupakan jenis penelitian yang dipilih oleh peneliti dalam penelitian ini dengan pendekatan kuantitatif. Pada penelitian ini peneliti memilih Perpustakaan Pusat Universitas Brawijaya sebagai lokasi penelitian. Data diperoleh melalui kuesioner 112 orang responden dipilih dalam penelitian ini untuk dijadikan sampel penelitian. Metode pengambilan sampel menggunakan teknik purposive sampling. Hasil penelitian membuktikan Citra Perusahaan, Citra Konsumen, dan Citra Produk secara bersama-sama berpengaruh signifikan terhadap Minat Beli.

Almuarief (2016) dengan judul penelitian Pengaruh Green Marketing Terhadap Minat Beli yang Dimediasi oleh Brand Image (Studi pada Air Minum Dalam Kemasan Ades). Penelitian yang dipilih oleh peneliti dalam penelitian ini dengan pendekatan kuantitatif. Diperoleh melalui kuesioner dari 140 responden yang dijadikan sampel. Hasil penelitian menunjukkan bahwa green marketing berpengaruh positif dan signifikan terhadap minat beli. Dengan demikian hipotesis kedua dalam penelitian ini diterima.

\section{Kerangka Pemikirian}

Kerangka pemikiran penelitian ini adalah sebagai berikut :

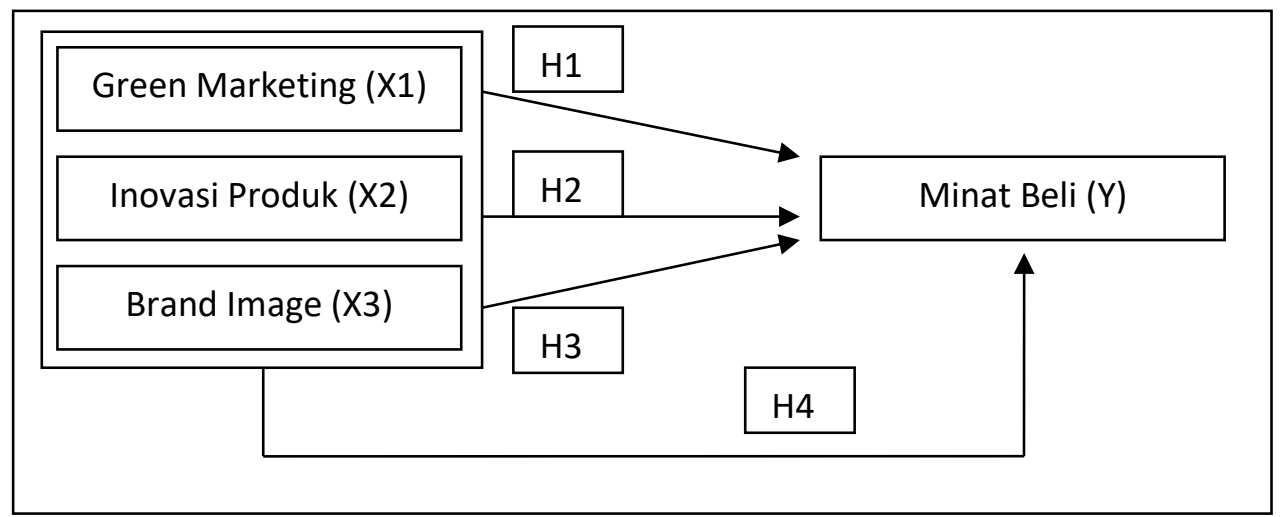

Gambar 1. Kerangka Pemikiran
Buying Intention of Students for Fastfood Product 


\section{Buying Intention of Hipotesis Penelitian}

Students for

Fastfood Product

Berdasarkan tujuan penelitian, perumusan masalah dan kerangka pemikiran di atas, peneliti memberikan hipotesis adalah sebagai berikut, yaitu :

H1 : Pengaruh Green Marketing terhadap Minat Beli pada KFC Yogyakarta

H2 : Pengaruh Inovasi Produk terhadap Minat Beli pada KFC Yogyakarta

H3 : Pengaruh Brand Image terhadap Minat Beli pada KFC Yogyakarta

H4 : Pengaruh Green Marketing, Inovasi Produk, dan Brand Image terhadap Minat Beli pada KFC Yogyakarta

\section{METODOLOGI PENELITIAN}

Penelitian ini dilakukan pada Mahasiswa dan Mahasiswi S1 Fakultas Ekonomi Universitas Sarjanawiyata Tamansiswa. Waktu penelitian dilaksanakan pada bulan November 2020 untuk uji coba terhadap instrumen penelitian dan membagikan kuesioner, dan Desember 2020 melakukan analisis data dan menyusun laporan penelitian. Pengumpulan data dalam penelitian ini menggunakan kuesioner, untuk memperoleh data responden mengenai green marketing, Inovasi Produk brand image dan minat beli Mahasiswa mahasiswi FE UST Konsumen KFC. Kuesioner yang digunakan adalah kuesioner pilihan ganda, dimana setiap item soal disediakan 5 (lima) pilihan jawaban.

Populasi penelitian ini adalah mahasiswa Mahasiswi FE UST Yogyakarta terdiri dari mahasiswa regular dan mahasiswa Karyawan yang terdaftar pada TU FE UST Yogyakarta sebanyak 2.822 orang. Jumlah sample penelitian ini sebanyak 100 orang responden yang ditentukan menggunakan metode rumus Slovin (1982) sebagai berikut:

$$
\mathrm{n}=\frac{2822}{1+\left(2822 \cdot 0,1^{2}\right)}=96,57 / 100 \text { Orang (dibulatkan) }
$$

Pengambilan sampel dilakukan dengan Pendekatan umum yang digunakan dalam penelitian ini yaitu Nonprobability sampling. Teknik yang dipakai adalah Purposive Sampling.

\section{Identifikasi Variabel}

1. Variabel independent (bebas) : Green Marketing (X1), Inovasi Produk (X2), dan Brand Image (X3).

2. Variabel dependent (terikat) yaitu : Minat Beli (Y1)

\section{HASIL DAN PEMBAHASAN}

Karakteristik Responden

1. Responden Berdasarkan Jenis Kelamin

Dari 100 responden, kebanyakan berjenis kelamin laki-laki yaitu sebanyak 62 dan yang berjenis kelamin perempuan sebanyak 88 orang.

Tabel 1 Karakteristik Responden Berdasarkan jenis kelamin.

\begin{tabular}{ll|r|r|r|r}
\multicolumn{2}{c}{ Jenis Kelamin } & Frequency & Percent & Valid Percent & Cumulative Percent \\
\hline Valid & Laki-laki & 62 & 41,3 & 41,3 & 41,3 \\
\cline { 2 - 6 } & Perempuan & 88 & 58,7 & 58,7 & 100,0 \\
\cline { 2 - 6 } & Total & 150 & 100,0 & 100,0 & \\
\hline
\end{tabular}

Sumber : Data primer diolah 2021

2. Responden Berdasarkan Usia

Tabel 2 Karakteristik Responden berdasarkan Usia.

\begin{tabular}{rlr|r|r|r}
\multicolumn{1}{l}{ Usia } & Frequency & Percent & Valid Percent & \multicolumn{2}{c}{ Cumulative Percent } \\
\hline Valid & 17-20 Tahun & 58 & 38,7 & 38,7 & 38,7 \\
\cline { 2 - 6 } & 21-25 Tahun & 91 & 60,7 & 60,7 & 99,3 \\
\cline { 2 - 6 } & 26-30 Tahun & 1 &, 7 &, 7 & 100,0 \\
\cline { 2 - 6 } & Total & 150 & 100,0 & 100,0 & \\
\hline
\end{tabular}

Sumber : Data primer diolah 2021 
Tabel 2 menunjukkan bahwa usia 17-20 tahun yaitu 58 orang, usia 21-25 tahun sebanyak 91 orang dan Usia 25-30 tahun sebanyak 1 orang. Dilihat dari uji tabel karakteristik responden berdasarkan dengan usia umur 21-25 lebih banyak mengkonsumsi KFC, karna pada usia segitu mereka lebih senang membeli makanan siap saji daripada memasak sendiri.

3. Responden Berdasarkan Program Study

Tabel 3 menunjukkan bahwa Prodi Manajemen yaitu 98 orang, sedangkan Prodi Akuntansi 52 orang.

Tabel 3 Karakteristik Responden berdasarkan Program Study

\begin{tabular}{lrr|r|rr}
\multicolumn{2}{c}{ Program Studi } & Frequency & \multicolumn{1}{c|}{ Percent } & Valid Percent & \multicolumn{2}{c}{ Cumulative Percent } \\
\hline Valid & Manajemen & 98 & 65,3 & 65,3 & 65,3 \\
\cline { 2 - 6 } & Akutansi & 52 & 34,7 & 34,7 & 100,0 \\
\cline { 2 - 6 } & Total & 150 & 100,0 & 100,0 & \\
\hline
\end{tabular}

Sumber : Data primer diolah 2021

4. Transaksi Membeli dalam 1 Tahun Terakhir

Tabel 4 Menujukan bahwa Transaksi membeli dalam 1 Tahun terakhir 1-10 kali yaitu 55 orang, transaksi 10-20 kali sebanyak 47 orang dan yang lebih dari 20 kali sebanyak 48 orang.

Tabel 4 Karakteritik Responden berdasarkan Transaksi

\begin{tabular}{llr|r|r|r}
\multicolumn{1}{c}{ Jumlah Transaksi } & Frequency & Percent & Valid Percent & \multicolumn{1}{c}{ Cumulative Percent } \\
\hline Valid & 55 & 36,7 & 36,7 & 36,7 \\
\cline { 2 - 6 } & $1-10$ kali & 47 & 31,3 & 31,3 & 68,0 \\
\cline { 2 - 6 } & Lebih dari 20 kali & 48 & 32,0 & 32,0 & 100,0 \\
\hline Total & 150 & 100,0 & 100,0 & \\
\hline
\end{tabular}

Sumber : Data primer diolah 2021

Tabel 5 : Uji Validas dan Reliabilitas Green Marketing(X1)

\begin{tabular}{|c|c|c|c|c|c|}
\hline Variabel & Butir & r-hitung & Keterangan & Koefisien Alpha Cronbach & Keterangan \\
\hline \multirow{10}{*}{$\begin{array}{c}\text { Green } \\
\text { Marketing }\end{array}$} & 1 & 0,730 & Valid & \multirow{10}{*}{0,904} & \multirow{10}{*}{ Reliabel } \\
\hline & 2 & 0,760 & Valid & & \\
\hline & 3 & 0,750 & Valid & & \\
\hline & 4 & 0,760 & Valid & & \\
\hline & 5 & 0,708 & Valid & & \\
\hline & 6 & 0,701 & Valid & & \\
\hline & 7 & 0,717 & Valid & & \\
\hline & 8 & 0,742 & Valid & & \\
\hline & 9 & 0,700 & Valid & & \\
\hline & 10 & 0,749 & Valid & & \\
\hline
\end{tabular}

Sumber: Data primer diolah 2021

Pada tabel 5 dijelaskan bahwa variabel Green Marketing memiliki nilai r-hitung lebih besar dari r-tabel $=0,1603$ maka dikatakan valid, dan nilai Koefisien Alpha Cronbach memiliki nilai lebih dari 0,7 maka dari itu dikatakan reliabel.

\section{Tabel 6 : Uji Validas dan Reliabilitas Inovasi Produk (X2)}

\begin{tabular}{|c|c|c|c|c|c|}
\hline Variabel & Butir & r-hitung & Keterangan & Koefisien Alpha Cronbach & Keterangan \\
\hline Inovasi & 1 & 0,802 & Valid & \multirow{8}{*}{0,900} & \multirow{8}{*}{ Reliabel } \\
\hline \multirow{7}{*}{ Produk } & 2 & 0,815 & Valid & & \\
\hline & 3 & 0,773 & Valid & & \\
\hline & 4 & 0,743 & Valid & & \\
\hline & 5 & 0,707 & Valid & & \\
\hline & 6 & 0,782 & Valid & & \\
\hline & 7 & 0,783 & Valid & & \\
\hline & 8 & 0,732 & Valid & & \\
\hline
\end{tabular}

Sumber: Data primer diolah 2021 
Buying Intention of Pada tabel 6 dijelaskan bahwa variabel Inovasi Produk memiliki nilai r-hitung lebih besar

Students for

Fastfood Product

$\underline{38}$ dar r-tabel $=0,1603$ maka dikatakan valid, dan nilai Koefisien Alpha Cronbach memiliki nilai lebih dari 0,7 maka dari itu dikatakan reliabel.

Tabel 7 : Uji Validas dan Reliabilitas Brand Image (X3)

\begin{tabular}{|c|c|c|c|c|c|}
\hline Variabel & Butir & r-hitung & Keterangan & Koefisien Alpha Cronbach & Keterangan \\
\hline Brand & 1 & 0,740 & Valid & \multirow{6}{*}{0,838} & \multirow{6}{*}{ Reliabel } \\
\hline \multirow[t]{5}{*}{ Image } & 2 & 0,727 & Valid & & \\
\hline & 3 & 0,746 & Valid & & \\
\hline & 4 & 0,770 & Valid & & \\
\hline & 5 & 0,758 & Valid & & \\
\hline & 6 & 0,722 & Valid & & \\
\hline
\end{tabular}

Sumber: Data primer diolah 2021

Pada tabel 7 dijelaskan bahwa variabel Brand Image memiliki nilai r-hitung lebih besar dar r-tabel $=0,1603$ maka dikatakan valid, dan nilai Koefisien Alpha Cronbach memiliki nilai lebih dari 0,7 maka dari itu dikatakan reliabel.

Tabel 8 : Uji Validas dan Reliabilitas Minat Beli (Y)

\begin{tabular}{|c|c|c|c|c|c|}
\hline Variabel & Butir & r-hitung & Keterangan & Koefisien Alpha Cronbach & Keterangan \\
\hline Minat & 1 & 0,669 & Valid & \multirow{9}{*}{0,868} & \multirow{9}{*}{ Reliabel } \\
\hline \multirow[t]{8}{*}{ Beli } & 2 & 0,707 & Valid & & \\
\hline & 3 & 0,733 & Valid & & \\
\hline & 4 & 0,655 & Valid & & \\
\hline & 5 & 0,699 & Valid & & \\
\hline & 6 & 0,735 & Valid & & \\
\hline & 7 & 0,718 & Valid & & \\
\hline & 8 & 0,705 & Valid & & \\
\hline & 9 & 0,666 & Valid & & \\
\hline
\end{tabular}

Sumber: Data primer diolah 2021

Pada tabel 8 dijelaskan bahwa variabel Minat Beli memiliki nilai r-hitung lebih besar dar r-tabel $=0,1603$ maka dikatakan valid, dan nilai Koefisien Alpha Cronbach memiliki nilai lebih dari 0,7 maka dari itu dikatakan reliabel.

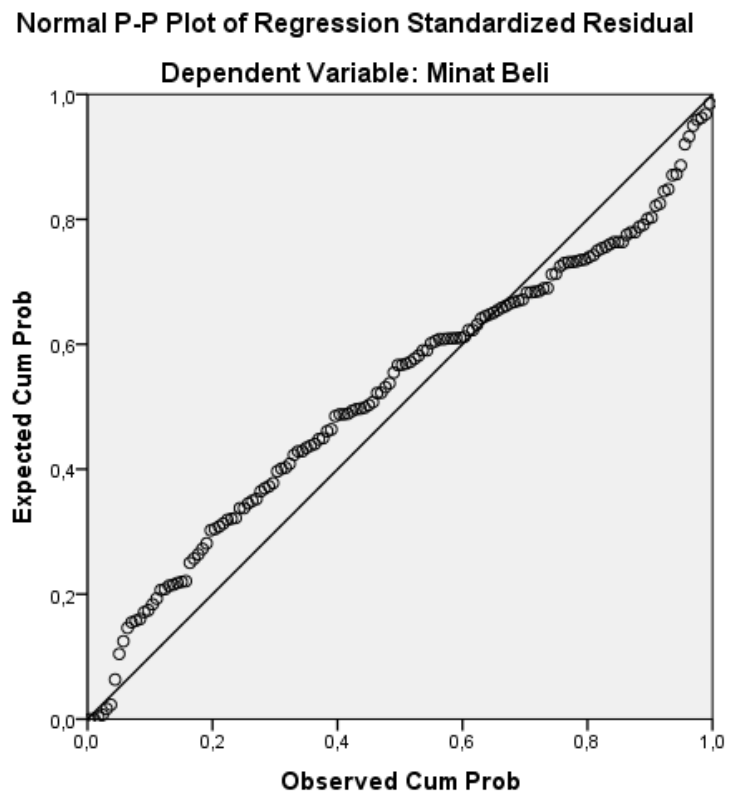

Gambar 1 : Hasil Uji Normalitas

Sumber: Data primer diolah 2021

Gambar 1 menunjukkan grafik normal plot terlihat data menyebar disekitar garis diagonal dan mengikuti arah garis diago nal atau grafik histogramnya menunjukkan pola berdistribusi normal, maka grafik normal plot memenuhi asumsi normalitas. 
Tabel 9 : Hasil Uji Multikolinieritas

\begin{tabular}{ll|r|r} 
& & \multicolumn{2}{|c}{ Collinearity Statistics } \\
Model & & Tolerance & \multicolumn{2}{c}{ VIF } \\
\hline 1 & (Constant) &, 890 & 1,123 \\
\cline { 2 - 4 } & Green Marketing &, 904 & 1,106 \\
\cline { 2 - 4 } & Inovasi Produk &, 959 & 1,043 \\
\cline { 2 - 4 } & Brand Image & &
\end{tabular}

Buying Intention of Students for Fastfood Product

a. Dependent Variable: Minat Beli

Sumber: Data primer diolah 2021

Tabel 9 menunjukkan semua nilai tolerance $>0,10$ atau nilai $\mathrm{VIF}<10$, sehingga tidak terjadi multikolinieritas.

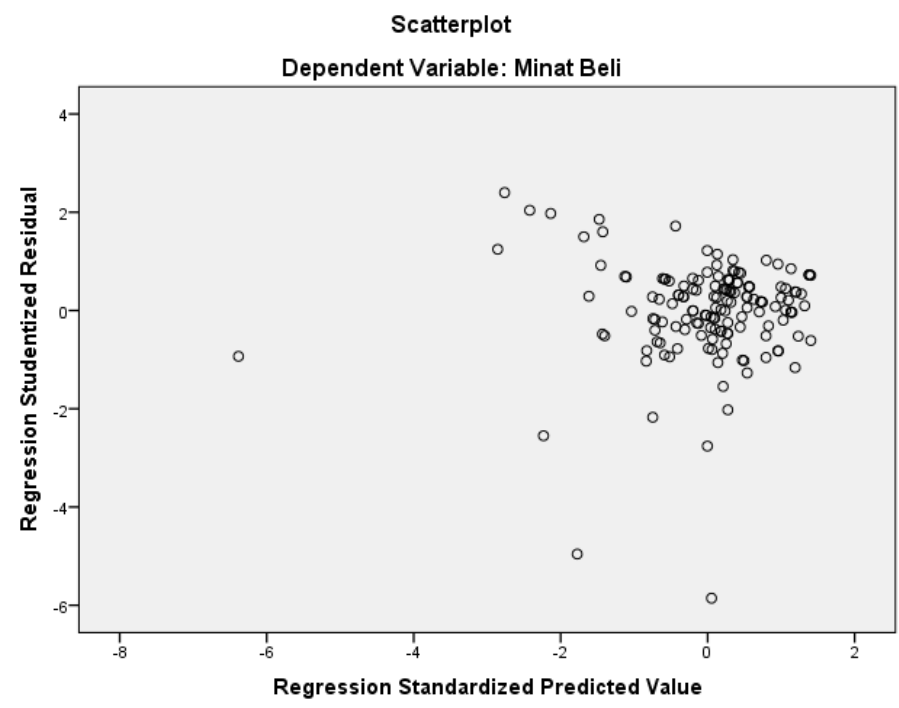

Gambar 2 : Hasil Uji Heteroskedastisitas

Sumber: Data primer diolah 2021

Gambar 2 menjelaskan bahwa titik- titik pada grafik scatterplot tidak membentuk pola tertentu dan menyebar disekitar titik 0 (nol). Hal ini menunjukkan bahwa tidak terjadi heteroskedastisitas.

Tabel 10 : Hasil Analisis Regresi Linier

\begin{tabular}{|c|c|c|c|c|c|}
\hline \multirow[t]{2}{*}{ Model } & \multicolumn{2}{|c|}{$\begin{array}{l}\text { Unstandardized } \\
\text { Coefficients }\end{array}$} & \multirow{2}{*}{$\begin{array}{c}\text { Standardized } \\
\text { Coefficients } \\
\text { Beta } \\
\end{array}$} & \multirow[t]{2}{*}{$\mathrm{t}$} & \multirow[t]{2}{*}{ Sig. } \\
\hline & $\mathrm{B}$ & Std. Error & & & \\
\hline 1 (Constant) & 9,128 & 4,766 & & 1,915 &, 057 \\
\hline Green Marketing &, 250 &, 078 & ,250 & 3,207 & ,002 \\
\hline Inovasi Produk & , 199 & ,094 &, 164 & 2,116 &, 036 \\
\hline Brand Image & ,414 &, 125 & ,249 & 3,314 &, 001 \\
\hline
\end{tabular}

a. Dependent Variable: Minat Beli

Sumber: Data primer diolah 2021

Berdasarkan Pada tabel diatas, maka dapat diperoleh persamaan regresi sebagai berikut : $\mathrm{MB}=\mathrm{a}+0,250 \mathrm{GM}+0,164 \mathrm{IP}+0,249 \mathrm{BI}+\mathrm{e}$

Persamaan tersebut menunjukkan koefisien beta pada variabel Green Marketing (X1), Inovasi Produk(X2) dan Brand Image(X3) bernilai positif, maka berpengaruh positif terhadap variabel Minat Beli(Y).

\section{Hasil Uji t}

Pengaruh Green Marketing terhadap Minat Beli

Hasil pengujian signifikansi menunjukkan bahwa variabel Green Marketing terdapat nilai sig t sebesar 0,002 yang berarti 0,002 $<0,05$ dengan nilai t hitung 3,207 lebih besar 
Buying Intention of Students for Fastfood Product

dari t tabel 1,98118 . Nilai tersebut dapat membuktikan bahwa Ho ditolak yang berarti bahwa Green Marketing berpengaruh terhadap Minat Beli.

Pengaruh Inovasi Produk terhadap Minat Beli

Hasil pengujian signifikansi menunjukkan bahwa variabel Inovasi Produk terdapat nilai sig t sebesar 0,036 yang berarti $0,036<0,05$ nilai t hitung 2,116 lebih besar dari $t$ tabel 1,98118. Nilai tersebut dapat membuktikan bahwa Ho ditolak yang berarti bahwa Inovasi Produk berpengaruh terhadap Minat Beli.

Pengaruh Komunikasi Brand Image terhadap Minat Beli

Hasil pengujian signifikansi menunjukkan bahwa variabel Brand Image terdapat nilai sig t sebesar 0,001 yang berarti 0,001 $<0,05$ nilai t hitung 3,314 lebih besar dari t tabel 1,98118. Nilai tersebut dapat dibuktikan bahwa Ho ditolak yang berarti bahwa Brand Image berpengaruh terhadap Minat Beli.

Tabel 11 : Hasil Uji F

\begin{tabular}{|c|c|c|c|c|c|}
\hline \multicolumn{6}{|c|}{ ANOVA $^{\mathrm{a}}$} \\
\hline Model & Sum of Squares & Df & Mean Square & $\mathrm{F}$ & Sig. \\
\hline 1 Regression & 810,006 & 3 & 270,002 & 12,910 &, $000^{\mathrm{b}}$ \\
\hline Residual & 3053,488 & 146 & 20,914 & & \\
\hline Total & 3863,493 & 149 & & & \\
\hline
\end{tabular}

a. Dependent Variable: Minat Beli

b. Predictors: (Constant), Brand Image, Inovasi Produk, Green Marketing

Sumber : Data primer diolah 2021

Berdasarkan tabel 11 nilai signifikan bernilai 0,000 atau kurang dari 0,05 maka dapat disimpulkan bahwa Green Marketing, Inovasi Produk dan Brand Image berpengaruh terhadap Minat Beli.

\section{Pembahasan}

Pengaruh Green Marketing terhadap Minat Beli.

Berdasarkan dari uji persial (t hitung) Green Marketing menghasilkan t hitung sebesar 3,207 dengan signifikansi 0,002. Hal ini menunjukkan bahwa variabel Green Marketing berpengaruh positif dan signifikan terhadap Minat Beli karena nilai signifikansinya kurang dari 0,05. Maka hipotesis yang menyatakan bahwa variabel Green Marketing berpengaruh positif dan signifikan terhadap Minat Beli "terbukti". Hasil penelitian ini juga mendukung penelitian yang sudah dilakukan oleh (Almuarif, 2016) menyatakan bahwa green marketing berpengaruh positif dan signifikan terhadap minat beli.

\section{Pengaruh Inovasi Produk terhadap Minat Beli.}

Berdasarkan dari uji persial (t hitung) Inovasi Produk menghasilkan t hitung sebesar 2,116 dengan signifikansi 0,036. Hal ini menunjukkan bahwa Inovasi Produk berpengaruh positif dan signifikan terhadap Minat Beli karena nilai signifikansinya kurang dari 0,05. Maka hipotesis yang menyatakan bahwa Inovasi Produk berpengaruh positif dan signifikan terhadap Minat Beli "terbukti". Hasil penelitian ini juga mendukung penelitian yang sudah dilakukan oleh (Almuarief, 2016) menyatakan bahwa terdapat pengaruh positif dan signifikan antara Inovasi Produk terhadap Minat Beli.

\section{Pengaruh Brand Image terhadap Minat Beli}

Berdasarkan dari uji persial (t hitung) Brand Image menghasilkan t hitung sebesar 3,314 dengan signifikansi 0,001. Hal ini menunjukkan bahwa Brand Image berpengaruh positif dan signifikan terhadap Minat Beli karena nilai signifikansinya kurang dari 0,05. Maka hipotesis yang menyatakan bahwa Brand Image berpengaruh positif dan signifikan terhadap Minat Beli "terbukti". Hasil penelitian ini juga mendukung penelitian yang sudah dilakukan oleh (Almuarief, 2016) menyatakan bahwa terdapat pengaruh positif dan signifikan antara Brand Image terhadap Minat Beli.

Pengaruh Green Marketing, Inovasi Produk dan Brand Image terhadap Minat Beli.

Berdasarkan dari uji Simultan ( F hitung) menghasilkan F hitung sebesar 12,910 dengan signifikansi 0,000. Hal ini menunjukkan bahwa Green Marketing, Inovasi Produk dan Brand Image berpengaruh positif dan signifikan terhadap Minat Beli karena nilai signifikansinya kurang dari 0,05 . Maka hipotesis yang menyatakan bahwa Green 
Marketing, Inovasi Produk dan Brand Image berpengaruh positif dan signifikan terhadap Minat Beli "terbukti".Hasil penelitian ini juga mendukung penelitian yang sudah dilakukan oleh (Septifani et al., 2014) green marketing, brand image berpengaruh positif dan signifikan terhadap minat beli.

\section{PENUTUP}

Berdasarkan hasil penelitian dan pembahasan penelitian diatas dapat disimpulkan sebagai berikut:

1. Terdapat pengaruh positif Green Marketing terhadap Minat Beli dalam Membeli Produk KFC pada mahasiswa Fakultas Ekonomi Universitas Sarjanawiyata Tamansiswa.

2. Terdapat pengaruh positif Inovasi Produk terhadap Minat Beli dalam membeli produk KFC pada mahasiswa Fakultas Ekonomi Universitas Sarjanawiyata Tamansiswa.

3. Terdapat pengaruh positif Brand Image terhadap Minat Beli dalam Membeli produk KFC pada mahasiswa Fakultas Ekonomi Universitas Sarjanawiyata Tamansiswa.

4. Terdapat pengaruh positif Green Marketing, Inovasi Produk, dan Brand Image terhadap Minat Beli dalam membeli produk KFC pada mahasiswa Fakultas Ekonomi Universitas Sarjanawiyata Tamansiswa.

\section{DAFTAR PUSTAKA}

[1] Agustin, R. D., \& Yulianto, E. (2015). DAMPAKNYA PADA KEPUTUSAN PEMBELIAN ( Survei Pada Konsumen Non-Member Tupperware Di Kota Malang ). Jurnal Administrasi Bisnis, 22(2), 37-36.

[2] Almuarief. (2016). Pengaruh Green Marketing terhadap Minat Beli yang dimediasi oleh Brand Image (Studi dalam Air Minum Kemasan Ades). IOSR1 Journal of Economics and Finance, 3(1), 56. https://doi.org/https://doi.org/10.3929/ethz-b000238666

[3] Ambarwati, M. (2015). Pengaruh Citra Merek Terhadap Minat Beli ( Survei Pada Mahasiswa Universitas Brawijaya Yang Menggunakan Pasta Gigi Pepsodent ). Jurnal Administrasi Bisnis, 25(1).

[4] AntaraNews. (2014). Produksi sampah plastik Indonesia 5,4 juta ton per tahun. 2014. Retrieved from https://www.antaranews.com/berita/417287/produksi-sampahplastik-indonesia-54-juta-ton-per-tahun

[5] CNBC Indonesia. (2019). Sebegini Parah Ternyata Masalah Sampah Plastik di Indonesia. 2019. Retrieved from https://www.cnbcindonesia.com/lifestyle

[6] Devi, P. I. S. (2014). Pengaruh Green Marketing Terhadap Minat Beli Konsumen Pada Produk The Body Shop. Universitas Kristen Maranatha, 1-8.

[7] Diponugroho, A. (2015). ANALISIS PENGARUH KUALITAS PRODUK DAN KEMAMPUAN INOVASI TERHADAP MINAT BELI ULANG DENGAN DAYA TARIK PRODUK SEBAGAI VARIABEL INTERVENING (Studi Kasus pada Parlour Café Semarang).

[8] Haryadi, R. (2018). PENGARUH STRATEGI GREEN MARKETING TERHADAP PILIHAN KONSUMEN MELALUI PENDEKATAN MARKETING MIX (Studi Kasus pada The Body Shop Jakarta). 7(7), 3442-3470.

[9] Https://marketing.co.id. (2012). KFC Praktikkan Bisnis Ramah Lingkungan. Marketing.Co.Id. Retrieved from https://marketing.co.id/kfc-praktikkan-bisnisramah-lingkungan/

[10] Ilham Tugiso, Andi Tri, M. M. M. (2016). Pengaruh relationship marketing, keamanan, kepercayaan dan kualitas pelayanan terhadap keputusan pembelian online shop dan loyalitas konsumen sebagai variabel intervening. 2(2).

[11] Istantia, S., Kumadji, S., \& Hidayat, K. (2016). PENGARUH GREEN MARKETING TERHADAP CITRA MEREK DAN KEPUTUSAN
Buying Intention of Students for Fastfood Product 
Buying Intention of

Students for

Fastfood Product
PEMBELIAN (Survei pada Pengguna Produk Ramah Lingkungan Lampu Philips LED di Perum Kepanjen Permai 1, RW 4, Desa Talangagung, Kec. Kepanjen, Malang, Jawa Timur). Jurnal Administrasi Bisnis S1 Universitas Brawijaya, 32(1), 174182.

[12] Kampani, P. (2014). DALAM KEPUTUSAN PEMBELIAN MOBIL ( Studi pada Konsumen PT Astra International Tbk . \pm TSO Malang Sutoyo ). 12(1), 1-8.

[13] Kotler, Philip, and K. L. K. (2012). Marketing Management. New Jersey: Prentice Hall Inc., (14th Edition).

[14] Kotler, P., Wilkie, L., \& Moore, E. S. (2005). The Role Played by the Broadening of Marketing Movement in the History of Marketing Thought. 24(2003), 114-116.

[15] Mc.Daniel, Stephen W. Rylander, D. H. (1993). Strategic Green Marketing. Journal of Consumer Marketing, 10(No. 3), 4-10.

[16] Noble, C. H., Sinha, R. K., \& Kumar, A. (2002). Market orientation and alternative strategic orientations : A longitudinal as ...

[17] Novita, Saputra, J. (2017). PENGARUH ELECTRONIC WORD OF MOUTH TERHADAP KEPUTUSAN PEMBELIAN PADA TOKO ONLINE. 03(01), 96-106.

[18] Prakash, A. (2002). Green Marketing, Public Policy and Managerial Strategies. Journal of Business Strategy and The Environment., 11 P, 285-297.

[19] Rafidah, I. (2017). ANALISIS KEAMANAN KEMUDAHAN DAN KEPERCAYAAN TERHADAP KEPUTUSAN PEMBELIAN SECARA ONLINE DI LAZADA Sekolah Tinggi Ilmu Ekonomi Indonesia (STIESIA) Surabaya. 6. I

[20] Mintarsih, C., \& Sulistiono, S. (2020). Pengaruh Personal Selling Dan Event Marketing Terhadap Minat Studi Lanjut Siswa SLTA Pada IBI Kesatuan. JAS-PT (Jurnal Analisis Sistem Pendidikan Tinggi Indonesia), 4(2), 125-136.

[21] Purnama, D., Muharam, H., \& Purba, J. H. V. (2018). HUBUNGAN ANTARA KUALITAS PELAYANAN DAN PERSONAL SELLING DENGAN KEPUASAN NASABAH BANK MANDIRI CABANG CISARUA. Economicus, 12(2), 101-112.

[22] Romadon, Y. (2014). PENGARUH GREEN MARKETING TERHADAP BRAND IMAGE DAN STRUKTUR KEPUTUSAN PEMBELIAN (Survei pada Followers Account Twitter@PertamaxIND Pengguna Bahan Bakar Ramah lingkungan Pertamax Series ). 15(1).

[23] Septifani, R., Achmadi, F., \& Santoso, I. (2014). Pengaruh Green Marketing, Pengetahuan. Jurnal Manajemen Teknologi, 13(2), 201-218.

[24] Sumarwan, U. A. . dkk. (2012). Riset Pemasaran dan Konsumen. PT Penerbit IPB Press., (Seri 2), 216.

[25] Suseno, S. B. (2004). ANALISIS FAKTOR-FAKTOR YANG MEMPENGARUHI INOVASI PRODUK UNTUK MENINGKATKAN KINERJA PEMASARAN.

[26] Tamamudin. (2012). Analisis Pengaruh Pengenalan Mere, Presepsi Kualitas, Harapan Konsumen dan Inovasi Produk terhadap keputusan Membeli dan Dampaknya Pada Loyalitas Konsumen (Studi Kasus: Produk batik sutra halus merek Tamina). Jurnal Penelitian, 9(2 November 2012), 283-300.

[27] Widodo, A., Yusiana, R., \& Stevanie, C. (2015). Pengaruh Green Marketing Terhadap Nilai Yang Dipersepsikan Dalam Keputusan Pembelian Pada Ades (Studi Kasus Pada Mahasiswa/I Fakultas Komunikasi Dan Bisnis Telkom University). Jurnal Ecodemica, 3(2), 529-538. Retrieved from http://ejournal.bsi.ac.id/ejurnal/index.php/ecodemica/article/view/49/13

[28] Www.clapeyronmedia.com. (2019). Darurat Sampah di Ibu Pertiwi - Clapeyron. Retrieved from http://www.clapeyronmedia.com/darurat-sampah-di-ibu-pertiwi/

[29] Yulianti, Rizka, D., Wulandari, D., \& Wulandari, G. A. (2014). Pengaruh Green Marketing dan Pengetahuan Serta Kepercayaan Terhadap Keputusan Pembelian Kosmetik Oriflame di SPO 857 Jember. Artikel Ilmiah Mahasiswa. 